\title{
Benefit of magnesium-25 carrying porphyrin- fullerene nanoparticles in experimental diabetic neuropathy
}

This article was published in the following Dove Press journal:

International Journal of Nanomedicine

15 July 2010

Number of times this article has been viewed

\begin{abstract}
Asieh Hosseini ${ }^{1}$
Mohammad Sharifzadeh'

Seyed Mahdi Rezayat ${ }^{2}$

Gholamreza Hassanzadeh ${ }^{3}$

Shokoufeh Hassani'

Maryam Baeeri'

Vahid Shetab-Bushehri ${ }^{4}$

Dmitry A Kuznetsov ${ }^{5}$

Mohammad Abdollahi'

'Faculty of Pharmacy, and

Pharmaceutical Sciences Research

Center, Tehran University of Medical

Sciences, Tehran, Iran; ${ }^{2}$ Faculty of

Advanced Science and Technology in

Medicine, Tehran University of Medical

Sciences and Pharmaceutical Sciences

Branch, Islamic Azad University,

Tehran, Iran; ${ }^{3}$ Faculty of Medicine,

Tehran University of Medical Sciences,

Tehran, Iran; ${ }^{4}$ Faculty of Medicine, Iran

University of Medical Sciences, Tehran,

Iran; ${ }^{5}$ Department of Medicinal

Nanobiotechnologies, N. I. Pirogoff

Russian State Medical University,

Moscow, Russian Federation
\end{abstract}

Correspondence: Mohammad Abdollahi Faculty of Pharmacy, and Pharmaceutical Sciences Research Center, and Endocrinology and Metabolism Research Institute, Tehran University of Medical Sciences, Tehran, Iran

Email mohammad.abdollahi@utoronto.ca

\begin{abstract}
Diabetic neuropathy $(\mathrm{DN})$ is a debilitating disorder occurring in most diabetic patients without a viable treatment yet. The present work examined the protective effect of ${ }^{25} \mathrm{Mg}-\mathrm{PMC}_{16}$ nanoparticle (porphyrin adducts of cyclohexil fullerene-C60) in a rat model of streptozotocin (STZ)-induced DN. ${ }^{25} \mathrm{Mg}-\mathrm{PMC}_{16}\left(0.5\right.$ lethal dose $\left.{ }_{50}\left[\mathrm{LD}_{50}\right]\right)$ was administered intravenously in two consecutive days before intraperitoneal injection of STZ (45 mg/kg). ${ }^{24} \mathrm{Mg}-\mathrm{PMC}_{16}$ and $\mathrm{MgCl}_{2}$ were used as controls. Blood 2,3-diphosphoglycerate (2,3-DPG), oxidative stress biomarkers, adenosine triphosphate (ATP) level in dorsal root ganglion (DRG) neurons were determined as biomarkers of DN. Results indicated that 2,3-DPG and ATP decreased whereas oxidative stress increased by induction of $\mathrm{DN}$ which all were improved in ${ }^{25} \mathrm{Mg}-\mathrm{PMC}_{16}$-treated animals. No significant changes were observed by administration of ${ }^{24} \mathrm{Mg}-\mathrm{PMC}_{16}$ or $\mathrm{MgCl}_{2}$ in $\mathrm{DN}$ rats. It is concluded that in $\mathrm{DN}$, oxidative stress initiates injuries to DRG neurons that finally results in death of neurons whereas administration of ${ }^{25} \mathrm{Mg}-\mathrm{PMC}_{16}$ by release of $\mathrm{Mg}$ and increasing ATP acts protectively.
\end{abstract}

Keywords: diabetes, neuropathy, ${ }^{25} \mathrm{Mg}$-magnetic isotope effect, porphyrin-fullerene nanoparticles, oxidative stress, adenosine triphosphate, nanotechnology

\section{Introduction}

The number of people with diabetes is developing due to population growth, aging, and increasing prevalence of obesity and physical inactivity. The total number of people with diabetes is estimated to rise from 171 million in 2000 to 366 million in $2030{ }^{1}$ Diabetic neuropathy (DN) usually develops in about $4 \%-10 \%$ of diabetic patients after five years and in $15 \%$ after 20 years. ${ }^{2}$ It is estimated that at least $50 \%$ of all diabetic patients will suffer from neuropathy in their lifetime. ${ }^{3}$

Hyperglycemia in diabetes causes an overflow of the polyol pathway, advanced glycation, oxidative stress, and deficiencies in neurotrophic factors. On the other hand, hypoinsulinemia results in mitochondrial dysfunction. Unfortunately, to date, a viable treatment for human $\mathrm{DN}$ is not available and all current drugs like tricyclic antidepressants, anticonvulsant agents, aldose reductase inhibitors, and drugs such as Y-linolenic acid, zenarestat, mexiletine and midodrine are only used for management. ${ }^{5}$ Oxidative stress is established to have a fundamental role in development of DN through induction of mitochondrial dysfunction, decline of adenosine triphosphate (ATP), and neural death. 2,3-diphosphoglycerate (2,3-DPG) as one of the factors contributing to tissue hypoxia is decreased in DN. Reduced levels of 2,3-DPG in DN result in a defect in delivery of oxygen to dorsal root ganglion (DRG) neurons leading to hypoxia and neuron death. It is believed that any rise in ATP and 2,3-DPG improve oxygenation. ${ }^{4-6}$ 
Recently, nanoparticles of a magnetic isotope of magnesium $\left({ }^{25} \mathrm{Mg}-\mathrm{PMC}_{16}\right)$ has been developed with low toxicity and membranotropic antioxidant effect. This nanoparticle, which possesses marked cationite properties, is the iron containing porphyrin monoadduct of a classical buckminster fullerene named "Porphylleren-MC16" or, in brief, $\mathrm{PMC}_{16}{ }^{25} \mathrm{Mg}$ isotopes that are released by this nanoparticle activate both substrate and oxidative phosphorylation pathways in acidosis condition and stimulate production of ATP in oxygen-depleted cells. ${ }^{7,8}$ Positive antiapoptotic and antioxidant effects of $\mathrm{Mg}$, fullerene, and porphyrin that exist within structure of this nanoparticle have been previously known. ${ }^{9-12}$

Regarding accumulation potential of this nanoparticle in the neuronal mitochondria, ${ }^{7}$ and the pathophysiology of DN, the hypothesis of this study was that ${ }^{25} \mathrm{MgPMC}_{16}$ by reduction of oxidative stress and increasing ATP in DRG neurons would protect mitochondrial dysfunction in DN. Therefore, the possible effects of ${ }^{25} \mathrm{Mg}-\mathrm{PMC}_{16}$ in an experimental model of DN were examined in comparison to nonmagnetic ${ }^{24} \mathrm{Mg}-\mathrm{PMC}_{16}$ and the ordinary form of $\mathrm{Mg}\left(\mathrm{MgCl}_{2}\right)$.

\section{Methods}

\section{Materials}

Adenosine diphosphate (ADP) sodium salt, ATP disodium salt, Tris base, 1,1,3,3-tetraethoxypropane (MDA), 5,5'dithiobis-2-nitro benzoic acid (DTNB), methanol (high performance liquid chromatography [HPLC]-grade), trichloroacetic acid (TCA), potassium hydroxide, $\mathrm{MgCl}_{2}$, diethyl ether, ketamine, xylazin, tetrabutylammonium hydroxide (TBAHS), n-butanol, 2-thiobarbituric acid (TBA), $\mathrm{KH}_{2} \mathrm{PO}_{4}$ (analytical grade), and 2,4,6-tripyridyl-s-triazine (TPTZ) from Merck (Tehran), streptozotocine (STZ) from Phar-

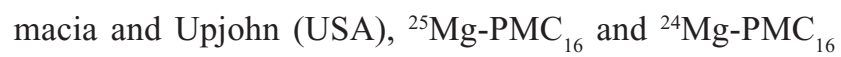
from Semenov institute (Russian Academy of Sciences), A SUPELCOSIL ${ }^{\text {TM }}$ LC-18-T HPLC column from SUPELCO (UK) and 2,3-DPG determination kit from Roche (Germany) were used in this study.

\section{Treatment}

Male Wistar rats weighing $200 \pm 5$ g were randomly divided in five groups with six rats in each group containing the control group that received nothing, DN group which received a single intraperitoneal (ip) injection of STZ (45 mg/kg), the protective group with ${ }^{25} \mathrm{Mg}-\mathrm{PMC}_{16}$ received two intravenous (iv) injections of ${ }^{25} \mathrm{Mg}-\mathrm{PMC}_{16}$ (0.5 lethal dose ${ }_{50}$ $\left[\mathrm{LD}_{50}\right]=448 \mathrm{mg} / \mathrm{kg}$ ) with 48 hours interval before receiving $\mathrm{STZ}$ by ip injection, the protective groups with ${ }^{24} \mathrm{Mg}-\mathrm{PMC}_{16}$ and $\mathrm{MgCl}_{2}$ received two iv injections of ${ }^{24} \mathrm{Mg}_{-} \mathrm{PMC}_{16}$ and
$\mathrm{MgCl}_{2}\left(0.5 \mathrm{LD}_{50}=448\right.$ and $88 \mathrm{mg} / \mathrm{kg}$, respectively) with two days intervals followed by a single ip injection of STZ. Different doses of the nanoparticle according to its $\mathrm{LD}_{50}$ and literature were selected and tested. At first, the work was started with $0.2 \mathrm{LD}_{50}$ according to previous study (7), but no suitable response was received. Then the dose was increased to $0.5 \mathrm{LD}_{50}$ and the proper effects were observed in all experiments.

In vivo studies were carried out according to ethical guidelines on the use of animals in research and the protocol was approved by institute review board.

\section{Induction of DN}

Experimental diabetes was induced by ip injection of dissolved STZ in normal saline with $\mathrm{pH}$ of 7 at the dose of $45 \mathrm{mg} / \mathrm{kg}$. Before an injection of STZ, animals were fasted for 12 hours. Within one week of injection, animals became hyperglycemic, with raised blood glucose between $250 \mathrm{mg} / \mathrm{dl}$ and $500 \mathrm{mg} / \mathrm{dl}$ that resulted in DN after two months. ${ }^{13}$

\section{Measurement of blood glucose and weight}

Blood glucose and weight of animals at the beginning of study and after two months were measured using a glucometer and a special balance.

\section{Sample preparation}

Sample preparation included blood, plasma, and tissues. At first, animals were anesthetized with intramuscular (im) injection of ketamine $(4 \mathrm{mg} / 100 \mathrm{~g})$ and xylazine $(1 \mathrm{mg} / 100 \mathrm{~g})$ mixture, then the abdomen was opened and blood $(5 \mathrm{ml})$ was collected from the heart into a heparinized syringe. Collected blood samples were centrifuged at $1200 \mathrm{~g}$ for $10 \mathrm{~min}$ at $4^{\circ} \mathrm{C}$ and plasma frozen at $-80^{\circ} \mathrm{C}$ until further analysis. For tissue preparation, after anesthetizing the animals, the spinal cord and paraspinal tissue from the second cervical to the second lumbar vertebra were removed altogether. Then the cervical spine laminae were removed until the spinal ganglia were exposed. The sixth cervical (C6) DRG on each side was removed and frozen quickly in liquid nitrogen.

\section{Measurement of 2,3-DPG}

This measurement was carried out using a kit. Since 2,3-DPG is too labile, the deproteinization procedure had to be performed immediately using perchloric acid (0.6 M) and potassium carbonate solution $(2.5 \mathrm{M})$. 2,3-DPG is stable for at least one day in the neutralized extracts and thus the samples were tested within 24 hours. 2,3-DPG is split by 
the side activity of phosphoglycerate mutase (PGM) to form phosphoglycerate (PG). Both, 2-PG and 3-PG can be formed. 2-PG is isomerized into 3-PG. 3-PG is converted by phosphoglycerate kinase (PGK), glyceraldehyde-3-phosphate dehydrogenase (GAP-DH), triosephosphate isomerase (TIM) and glycerol-3-phosphate dehydrogenase (GDH). Meanwhile, 2 mole of nicotinamide adenine dinucleotide $(\mathrm{NADH})$ is oxidized per mole of 2,3-DPG. Then absorption of NADH was determined at $340 \mathrm{~nm} .{ }^{14}$

\section{Measurement of total plasma antioxidant capacity}

The ability of plasma to reduce $\mathrm{Fe}^{3+}$ to $\mathrm{Fe}^{2+}$ is an indicator of plasma antioxidant capacity. The complex between $\mathrm{Fe}^{2+}$ and 2,4,6-tris(2-pyridyl)-1,3,5-triazine(TPTZ) gives a blue color with absorbance at $593 \mathrm{~nm}$ that is read by spectrophotometer. ${ }^{15}$

\section{Measurement of plasma total thiol groups}

Total sulfhydryl level was determined as described previously. ${ }^{16}$ A plasma volume of $0.2 \mathrm{ml}$ was mixed with $0.6 \mathrm{ml}$ of Tris - EDTA buffer [Tris base (0.25 M), EDTA (20 mM), pH 8.2] in a $10 \mathrm{ml}$ test tube and then mixed with $40 \mathrm{ml}$ of DTNB (10 $\mathrm{mM}$ ) in methanol. The final volume was made up to $4.0 \mathrm{ml}$ by adding $3.16 \mathrm{ml}$ of methanol. The test tube, after capping, centrifuged at $3000 \mathrm{~g}$ for $10 \mathrm{~min}$ at ambient temperature. After 15-20 min, the color appeared. The absorbance of the supernatant was measured at $412 \mathrm{~nm} .{ }^{16}$

\section{Measurement of lipid peroxidation (LPO)}

LPO of plasma was measured by the reaction of TBA with MDA and other lipid peroxides. Plasma samples were mixed with TCA $(20 \%)$ and the produced precipitate was dispersed in $\mathrm{H}_{2} \mathrm{SO}_{4}(0.05 \mathrm{M})$. After addition of TBA $(0.2 \%$ in sodium sulfate) the samples were heated for 30 minutes in a boiling water bath. Then LPO adducts were extracted by n-butanol and absorbance was read at $532 \mathrm{~nm} .{ }^{17}$

\section{Measurement of adenosine diphosphate (ADP) and ATP}

The frozen DRG was removed on ice and was quickly homogenized $\left(4^{\circ} \mathrm{C}\right)$ in $1 \mathrm{~mL}$ of ice-cold $6 \%$ TCA. The homogenate was centrifuged at $12000 \mathrm{~g}$ for $10 \mathrm{~min}$ at $4^{\circ} \mathrm{C}$. The supernatant was neutralized to a $\mathrm{pH}$ of 6.5 with $4 \mathrm{M} \mathrm{KOH}$. Then it was filtered through a millipore filter (pore size $0.45 \mu \mathrm{m}$ ), and the neutralized extract was used to determine the concentrations of ATP and ADP $(\mu \mathrm{g} / \mathrm{mL}$ per mg of tissue) using ion pair-high performance liquid chromatography (IP-HPLC). Standard solutions of ATP and ADP were used to get a standard curve and then samples were tested to express energy changes as an ADP/ATP ratio. ${ }^{18}$

\section{Statistical analysis}

All values were expressed as a mean \pm standard error (SE). Data was statistically analyzed by analysis of variance (ANOVA) followed by Newman-Keuls using Stat Direct version 2.7.7. $P$-Values less than 0.05 were considered statistically significant.

\section{Results}

\section{Animal's weight and blood glucose}

Weights of DN rats significantly reduced as compared with control rats $(P<0.001)$. Blood glucose in DN rats significantly increased as compared to control rats $(P<0.001)$. After use of ${ }^{25} \mathrm{MgPMC}_{16}$, a significant increase in animal weight and decrease in glucose level were observed ( $P<0.01$ and $P<0.05$, respectively) when compared to $\mathrm{DN}$ rats. No significant changes were observed by use of ${ }^{24} \mathrm{Mg}_{-} \mathrm{PMC}_{16}$ and $\mathrm{MgCl}_{2}$ (Figures 1 and 2).

\section{Blood 2,3-DPG}

There was a significant decrease in 2,3-DPG concentration in DN group $(P<0.001)$ as compared to control rats but administration of ${ }^{25} \mathrm{Mg}-\mathrm{PMC}_{16}$ caused a significant increase of this marker $(P<0.001)$. No significant changes were observed by administration of ${ }^{24} \mathrm{Mg}-\mathrm{PMC}_{16}$ and $\mathrm{MgCl}_{2}$ in DN rats (Figure 3 ).

\section{Biomarkers of oxidative stress}

A significant decrease in total antioxidant capacity and total thiol molecules ( $P<0.01$ and $P<0.05$, respectively) and an increase of LPO $(P<0.001)$ in DN group were recorded in comparison to controls. Administration of ${ }^{25} \mathrm{Mg}-\mathrm{PMC}_{16}$ increased total antioxidant capacity and total thiol molecules ( $P<0.01$ and $P<0.001$, respectively) and decreased LPO $(P<0.01)$ as compared to DN group. No significant changes were detected by administration of ${ }^{24} \mathrm{Mg}-\mathrm{PMC}_{16}$ and $\mathrm{MgCl}_{2}$ (Table 1).

\section{ATP and ADP in DRG neurons}

As observed in Figure 4, a significant increase in ADP/ATP ratio in $\mathrm{DN}$ rats is evident in comparison to the control group $(P<0.001)$. The administration of ${ }^{25} \mathrm{Mg}-\mathrm{PMC}_{16}$ reduced the $\mathrm{ADP} / \mathrm{ATP}$ ratio in comparison to the $\mathrm{DN}$ group $(P<0.001)$. ${ }^{24} \mathrm{Mg}-\mathrm{PMC}_{16}$ and $\mathrm{MgCl}_{2}$ caused no significant changes. 


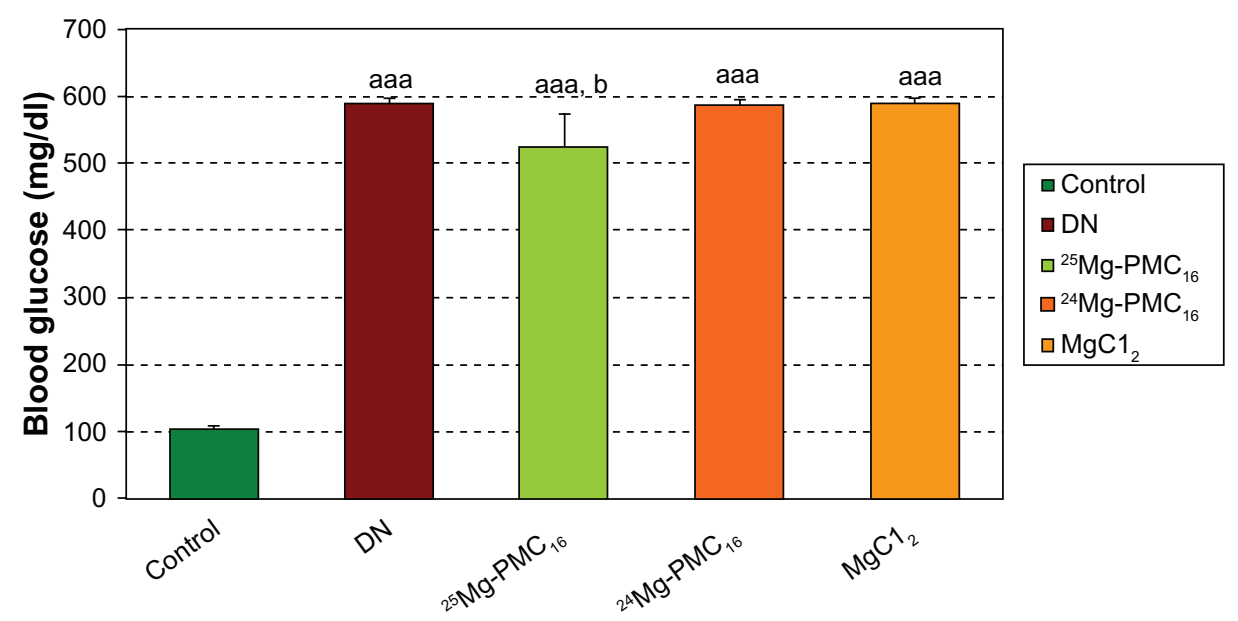

Figure I Protective effects of various forms of magnesium on blood glucose in DN rats after two months.

Notes: Data are mean \pm SE of six animals. Difference between control and other groups is significant at $P<0.001$ (aaa). Difference between $\mathrm{DN}$ and ${ }^{25} \mathrm{Mg}$-PMC ${ }_{16}$ is significant at $P<0.05($ b).

Abbreviations: DN, diabetic neuropathy; SE, standard error.

\section{Discussion}

The present findings indicate a significant improvement in biomarkers of DN including blood 2,3-DPG and oxidative stress, DRG neuronal ADP/ATP by use of ${ }^{25} \mathrm{Mg}-\mathrm{PMC}_{16}$. Interestingly no considerable improvement was found in $\mathrm{DN}$ when ${ }^{24} \mathrm{Mg}-\mathrm{PMC}_{16}$ or $\mathrm{MgCl}_{2}$ were used.

The unique structure of ${ }^{25} \mathrm{Mg}-\mathrm{PMC}_{16}$ as a nanocationite helps smart release of $\mathrm{Mg}$ into DN cells that are in hypoxic acidosis condition and imbalance of oxidative phosphorylation and ATP. Meanwhile, the porphyrin domain of $\mathrm{PMC}_{16}$ provides a tissue selective interaction for porphyrin receptors located in the mitochondrial membrane. It seems that water-soluble $\mathrm{C} 60$-fullerene derivatives have the ability to selectively accumulate inside mammalian mitochondria. ${ }^{7}$ This nanoparticle is safe for use, because the hepatic turnover of $\mathrm{PMC}_{16}$ occurs mainly on the porphyrin domain that forms biologically neutral heme precursor. The hepatic metabolites include alanyl-depleted $\mathrm{PMC}_{16}$ (54.6\% of total metabolites amount), deacetylated $\mathrm{PMC}_{16}$ derivatives $(27.0 \%)$ and cyclohexyl C60-fullerene (16.2\%). In hypoxia, $\mathrm{PMC}_{16}$ becomes more resistant to hepatic metabolism. ${ }^{7}$ Therefore, besides $\mathrm{Mg}$, these metabolites themselves may have useful effects in DN.

As found in the present study, 2,3-DPG is one of the factors contributing to tissue hypoxia significantly decreased in DN. During glycolysis, metabolism can be diverted into the Rapoport-Luebering shunt, generating 2,3-DPG instead of ATP. 2,3-DPG binds to deoxyhemoglobin to modulate oxygen affinity and unloading of oxygen at the capillaries. It is believed that, reduced levels 2,3-DPG in DN result in a defect

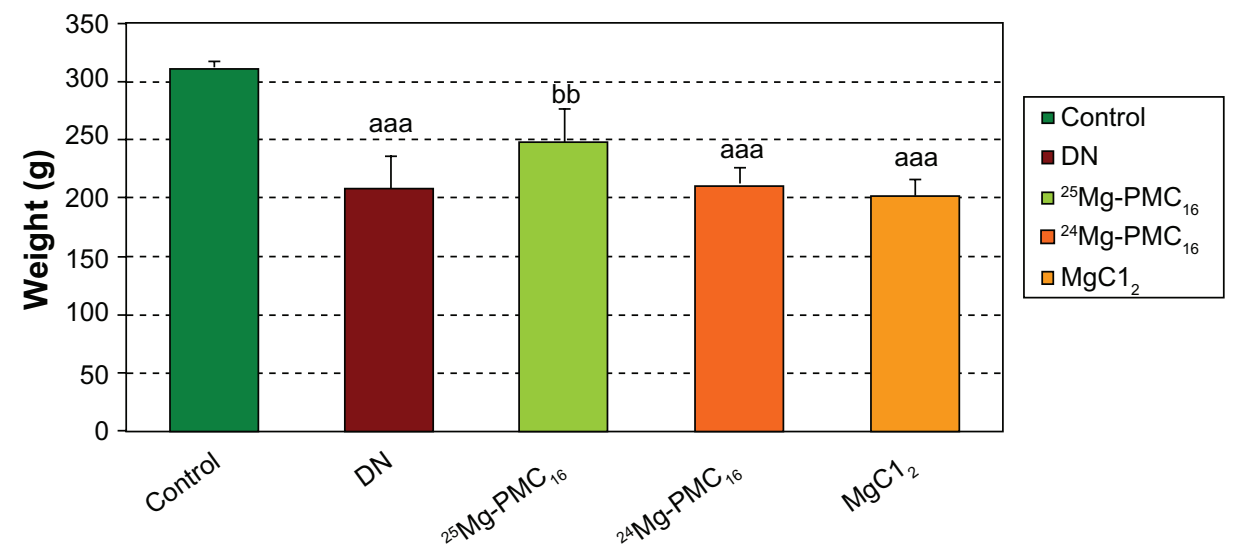

Figure 2 Protective effects of various forms of magnesium on weight of DN rats after two months.

Notes: Data are mean $\pm \mathrm{SE}$ of six animals. Difference between control and other groups is significant at $P<0.00 \mathrm{I}\left({ }^{\text {(aaa }}\right)$. Difference between $\mathrm{DN}$ and ${ }^{25} \mathrm{Mg}$-PMC $\mathrm{C}_{16}$ is significant at $P<0.05\left({ }^{(b)}\right)$.

Abbreviations: DN, diabetic neuropathy; SE, standard error. 


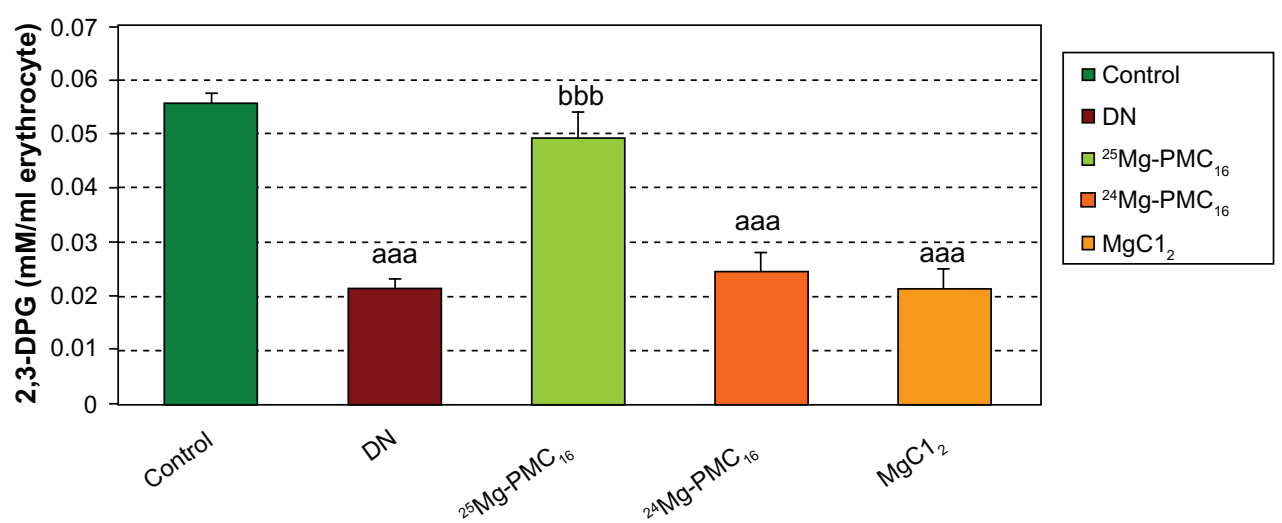

Figure 3 Protective effects of various forms of magnesium on 2,3-DPG concentration in erythrocytes of DN rats after two months.

Notes: Data are mean \pm SE of six animals. Difference between control and other groups is significant at $P<0.00 \mathrm{I}$ (aaa). Difference between $\mathrm{DN}$ and ${ }^{25} \mathrm{Mg}$-PMC ${ }_{16}$ is significant at $P<0.001\left({ }^{\text {bbb }}\right)$.

Abbreviations: DN, diabetic neuropathy; SE, standard error.

in oxygen delivery within DRG neurons and followed by hypoxia and neuron death. ${ }^{19,20}$ As far as we know, 2,3-DPG and ATP decrease the affinity of the hemoglobin for oxygen and a close inverse correlation was found between the oxygen binding and the concentration of these phospho compounds in intact human erythrocytes. ATP and 2,3-DPG have approximately equal effect on hemoglobin oxygenation. However, binding of both phospho compounds decreased at higher hydrogen ion concentrations in DN because of hypoxia and followed acidosis. ${ }^{21}$ Thus it seems that ${ }^{25} \mathrm{Mg}-\mathrm{PMC}_{16}$ increases 2,3-DPG level via three mechanisms. First of all, the increased ATP by ${ }^{25} \mathrm{Mg}-\mathrm{PMC}_{16}$ in hypoxic condition and reduced 2,3DPG in DN, bind to hemoglobin compensational in the way to deliver oxygen to DRG neurons. Second of all, in oxygenated erythrocytes that contain a relatively high concentration of $\mathrm{Mg}$, it is estimated that almost all of the $\mathrm{Mg}$ is bound to ATP and with somehow lesser affinity to 2,3-DPG. ${ }^{22}$ Therefore it seems that, deoxygenated erythrocytes in $\mathrm{DN}$, causes complex of Mg and 2,3-DPG to be dissociated easier than that of $\mathrm{Mg}$ and ATP due to increased ATP and $\mathrm{Mg}$ by ${ }^{25} \mathrm{Mg}-\mathrm{PMC}_{16}$ and high affinity of $\mathrm{Mg}$ to ATP. Thus, this leads to increased 2,3-DPG concentration. Finally, in the process of 2,3-DPG production in erythrocytes (Rapoport-Luebering shunt), 1,3-diphosphoglyceric acid is converted to 3-phosphoglyceric acid by phosphoglycerate kinase (PGK) and then to 2,3-DPG by a kinase in the presence of ATP. ${ }^{23}$ Therefore, ${ }^{25} \mathrm{Mg}-\mathrm{PMC}_{16}$ with improving PGK enzyme activity ${ }^{24}$ and ATP level proceeds the pathway to increase 2,3-DPG in DN.

The present findings also showed a significant increase in oxidative stress biomarkers in DN that is supported by previous studies. DRG neurons have large mitochondria with high oxidative metabolism making them much susceptible to oxidative injury. The chronic distal sensory deficits that are seen in chronic DN might be more closely related to DRG neurons because the blood-nerve and perineurial barriers are minor at this site. ${ }^{25}$ Increased ADP/ATP ratio in DRG neurons in $\mathrm{DN}$ group is considered as a marker of mitochondrial dysfunction in neurons. Mitochondrial dysfunction itself is a central mediator of neural apoptosis in the peripheral nervous system and a critical modulator of diabetic neuropathy. ${ }^{4}$ In diabetes, reactive oxygen species (ROS) that are coupled with depolarization of the inner mitochondrial membrane $\left(\Delta \Psi_{\mathrm{Mt}}\right)$ are associated with an increase in the ADP/ATP ratio and an absolute decrease in ATP levels. Also increased metabolic flux in the mitochondria due to high glucose is coupled with reduction of NAD to NADH that results in further formation of ROS. Accumulation of NADH coupled with failure of mitochondrial creatine phosphate pump in regeneration of

Table I Protective effects of various forms of magnesium on oxidative stress biomarkers

\begin{tabular}{llllll}
\hline & Control & DN & ${ }^{25} \mathbf{M g}-\mathbf{P M C}_{16}$ & ${ }^{24} \mathbf{M g} \mathbf{P M C}_{16}$ & $\mathbf{M g C l}_{2}$ \\
\hline $\begin{array}{l}\text { Total antioxidant capacity } \\
(\mu \mathrm{mol} / \mathrm{mL})\end{array}$ & $566.2 \pm 46.44$ & $325.7 \pm 32.9^{\text {aa }}$ & $540.7 \pm 39.82^{\text {bb }}$ & $344.3 \pm 33.89^{\text {aa }}$ & $370.5 \pm 40.60^{\text {a }}$ \\
Lipid peroxidation $(\mathrm{nmol} / \mathrm{mL})$ & $1.73 \pm 0.18$ & $5.17 \pm 0.45^{\text {aaa }}$ & $2.54 \pm 0.47^{\text {bb }}$ & $4.85 \pm 0.53^{\text {aa }}$ & $4.8 \pm 0.55^{\text {aa }}$ \\
Total thiol groups $(\mathrm{mmol} / \mathrm{L})$ & $0.53 \pm 0.05$ & $0.26 \pm 0.06^{\mathrm{a}}$ & $0.47 \pm 0.04^{\text {bb }}$ & $0.28 \pm 0.04^{\mathrm{a}}$ & $0.28 \pm 0.03^{\mathrm{a}}$ \\
\hline
\end{tabular}

Notes: Data are mean \pm SE of six animals. Difference between control and other groups is significant at $P<0.001$ (aaa), $P<0.01$ ( (a) $), P<0.05\left({ }^{a}\right)$. Difference between DN and ${ }^{25} \mathrm{Mg}_{-} \mathrm{PMC}_{16}$ is significant at $P<0.00 \mathrm{I}\left({ }^{\mathrm{bbb}}\right), P<0.01\left({ }^{(\mathrm{bb}}\right)$.

Abbreviations: DN, diabetic neuropathy; SE, standard error. 


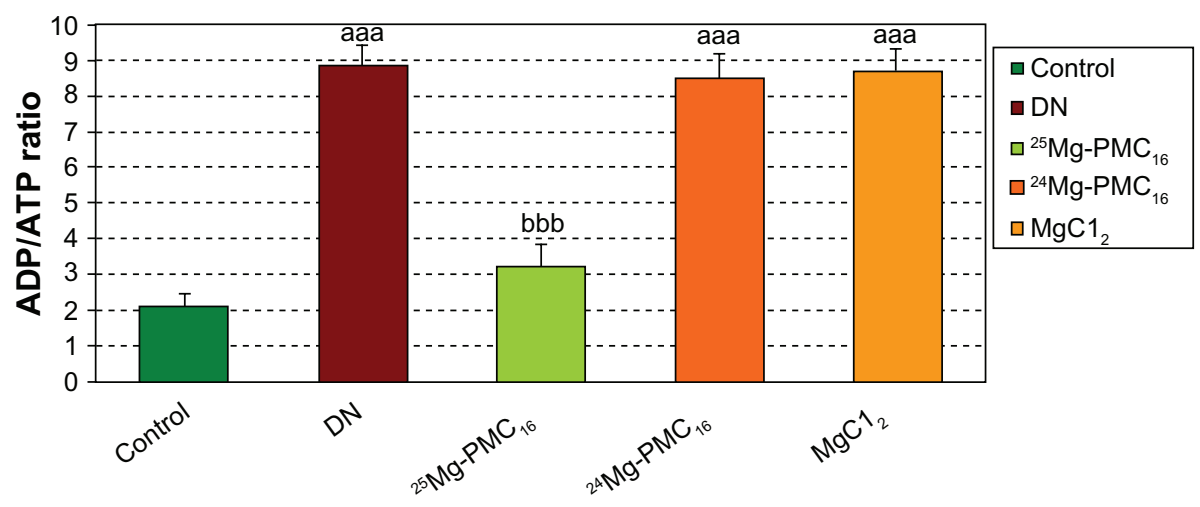

Figure 4 Protective effects of various forms of magnesium on ADP/ATP level in DN rats after two months.

Notes: Data are mean $\pm \mathrm{SE}$ of six animals. Difference between control and other groups is significant at $P<0.00 \mathrm{I}\left(\right.$ aaa). Difference between $\mathrm{DN}$ and ${ }^{25} \mathrm{Mg}$-PMC $\mathrm{C}_{16}$ is significant at $P<0.001{ }^{\left({ }^{b b}\right)}$.

Abbreviations: ADP/ATP, adenosine diphosphate/adenosine triphospahte; DN, diabetic neuropathy; SE, standard error.

ATP from ADP disrupts electron transfer chain and therefore results in DRG neuron death. ${ }^{26}$

Decreased 2,3-DPG and hypoxia and further acidosis in DN conditions activates ${ }^{25} \mathrm{Mg}$ - $\mathrm{PMC}_{16}$ and therefore positive effects of magnetic $\mathrm{Mg}$ is guaranteed. ${ }^{7}$ There is evidence that fullerenes that exist in structure of ${ }^{25} \mathrm{Mg}-\mathrm{PMC}_{16}$ have antioxidant and anti-apoptotic effects due to their potential to react with ROS. ${ }^{9}$ Other studies have shown that both lipophilic and hydrophilic C60 derivatives have wonderful potential as medicines for treating LPO-related diseases. ${ }^{27-29}$ Apoptosis is a programmed cell death that is mainly due to the change in growth factor. In this condition, ROS are released, thus, therapies targeted against ROS are greatly useful for minimizing cellular damage in oxidative stress-mediated neurodegeneration and other ROS-dependent disorders. ${ }^{30,31}$ Fullerene derivatives have also anti-apoptotic activity and can prevent apoptosis by neutralization of tumor growth factor (TGF)-induced ROS, reduction of tumor necrosis factor (TNF) or ultraviolet-triggered activation of caspases. In addition, fullerene derivatives associate with mitochondria more efficiently than conventional antioxidants. ${ }^{9,32}$ On the other hand, ${ }^{25} \mathrm{Mg}-\mathrm{PMC}_{16}$ by releasing $\mathrm{Mg}$ in $\mathrm{DN}$ hypoxic conditions induces antioxidant and anti-apoptotic effects. It has been shown that $\mathrm{Mg}$ has a dosedependent neuroprotective effect after a spinal cord injury that is mediated by reduction of neuronal LPO. ${ }^{11}$ Also it was found that $\mathrm{MgSO}_{4}$ decreases neuron apoptosis after cerebral ischemia-reperfusion injury through suppression of caspase-3 and bax expression. ${ }^{12}$ Another study showed that $\mathrm{MgSO}_{4}$ significantly inhibits endotoxin-induced up-regulation of inflammatory molecules and NF- $\mathrm{K} \beta$ activation. ${ }^{33} \mathrm{Mg}$ has been also found effective in human poisoning with organophosphates that act through inhibition of cholinesterase and induction of oxidative stress. ${ }^{34}$ Considering the study indicated a decrease in body $\mathrm{Mg}$ concentration in diabetes type 1 patients, ${ }^{35}$ it is not surprising to conclude that any elevation of intraneuronal $\mathrm{Mg}$ is a helpful strategy in the management of DN. Of course it should not be forgotten that we saw positive effects only for ${ }^{25} \mathrm{Mg}-\mathrm{PMC}_{16}$ and not for other forms like ${ }^{24} \mathrm{Mg}-\mathrm{PMC}_{16}$ and $\mathrm{MgCl}_{2}$ that were tested in the present study. Thus, the first idea that comes to mind is the problem that might exist in reaching and accumulating of adequate $\mathrm{Mg}$ into neurons. In the plasma with normal $\mathrm{pH}$ of $7.4,{ }^{25} \mathrm{Mg}-\mathrm{PMC}_{16}$ cannot easily release $\mathrm{Mg}$ but hypoxic condition in $\mathrm{DN}$ when inside the cells will change to acidic $\mathrm{pH}$, then ${ }^{25} \mathrm{Mg}-\mathrm{PMC}_{16}$ will be able to release $\mathrm{Mg}$ so easily resulting in a dramatical increase of $\mathrm{Mg}$ inside DRG cells. On the other hand since equal doses of these three forms of $\mathrm{Mg}$ has been tested, thus one can conclude that magnetic $\mathrm{Mg}$ plays the effective role much better than other forms of $\mathrm{Mg}$. Taking collectively, the present finding confirms that ${ }^{25} \mathrm{Mg}$ $\mathrm{PMC}_{16}$ protects from STZ-induced DN through reduction of oxidative stress and improving ATP by better reaching neuronal cells and release of $\mathrm{Mg}$. Of course positive role of fullerene structure of ${ }^{25} \mathrm{Mg}-\mathrm{PMC}_{16}$ cannot be ignored.

\section{Acknowledgment}

This work was supported in part by funds from Tehran University of Medical Sciences. The authors report no conflicts of interest in this work.

\section{References}

1. Wild S, Roglic G, Green A, Sicree R, King H. Global prevalence of diabetes: estimates for the year 2000 and projections for 2030. Diabetes Care. 2004;27(5):1047-1053.

2. Raymond Azman A. Management of diabetic neuropathy. Malaysian Journal of Medical Science. 2003;10(2):27-30.

3. Figueroa-Romero C, Sadidi M, Feldman EL. Mechanisms of disease: the oxidative stress theory of diabetic neuropathy. Rev Endocr Metab Disord. 2008;9(4):301-314. 
4. Fernyhough P, Huang TJ, Verkhratsky A. Mechanism of mitochondrial dysfunction in diabetic sensory neuropathy. J Peripher Nerv Syst. 2003; 8(4):227-235

5. Douglas W, Zochodne MD. Diabetic Neuropathies. Neuromuscul Disord. 2000;2:23-29.

6. Rahimi R, Nikfar S, Larijani B, Abdollahi M. A review on the role of antioxidants in the management of diabetes and its complications. Biomed Pharmacother. 2005;59(7):365-373.

7. Rezayat SM, Boushehri SV, Salmanian B, et al. The porphyrin-fullerene nanoparticles to promote the ATP overproduction in myocardium: $25 \mathrm{Mg} 2^{+}$-magnetic isotope effect. Eur J Med Chem. 2009;44(4): 1554-1569.

8. Amirshahi N, Alyautdin RN, Sarkar S, et al. Porphyrin-fullerene nanoparticles for treatment of hypoxic cardiopathies. Nanotechnol Russ. 2008;3(10):611-621.

9. Bosi S, Da Ros T, Spalluto G, Prato M. Fullerene derivatives: an attractive tool for biological applications. Eur J Med Chem. 2003;38(11-12): 913-923.

10. Wu AS, Kiaei M, Aguirre N, et al. Iron porphyrin treatment extends survival in a transgenic animal model of amyotrophic lateral sclerosis. J Neurochem. 2003;85(1):142-150.

11. Süzer T, Coskun E, Islekel H, Tahta K. Neuroprotective effect of magnesium on lipid peroxidation and axonal function after experimental spinal cord injury. Spinal Cord. 1999;37(7):480-484.

12. Zhou H, Ma Y, Zhou Y, Liu Z, Wang K, Chen G. Effects of magnesium sulfate on neuron apoptosis and expression of caspase-3, bax and bcl-2 after cerebral ischemia-reperfusion injury. Chin Med J (Engl). 2003;116(10):1532-1534.

13. Srinivasan S, Stevens M, Wiley JW. Diabetic peripheral neuropathy: evidence for apoptosis and associated mitochondrial dysfunction. Diabetes. 2000;49(11):1932-1938.

14. Castilho EM, Glass ML, Manço JC. The effects of 2,3-diphosphoglycerate, adenosine triphosphate, and glycosylated hemoglobin on the hemoglobin-oxygen affinity of diabetic patients. Braz J Med Biol Res 2003;36(6):731-737.

15. Benzi IF, Strain S. Ferric reducing antioxidant power assay: direct measure of total antioxidant activity of biological fluids and modified version for simultaneous measurement of total antioxidant power and ascorbic acid concentration. Methods Enzymol. 1999;292:15-27.

16. Hu ML, Dillared CJ. Plasma SH and GSH measurement. Methods Enzymol. 1994;233:385-387.

17. Ranjbar A, Solhi H, Jalali Mashayekhi F, Susanabdi A, Rezaie A, Abdollahi M. Oxidative stress in acute human poisoning with organophosphorus insecticides; a case control study. Environ Toxicol Pharmacol. 2005;20(1):88-91.

18. Chen Y, Xing D, Wang W, Ding Y, Du L. Development of an ion-pair HPLC method for investigation of energy charge changes in cerebral ischemia of mice and hypoxia of Neuro-2a cell line. Biomed Chromatogr. 2007;21(6):628-634.

19. Lewis R Goldfrank, Neal Flomenbaum, Mary Ann Howland, Robert S Hoffman, Neal A Lewin, Lewis S Goldfranks. Toxicologic Emergencies. 8th ed. Nelson-Medical; 2006:238.
20. Nakamura J, Koh N, Sakakibara F, et al. Polyol pathway, 2,3diphosphoglycerate in erythrocytes and diabetic neuropathy in rats. Eur J Pharmacol. 1995;294(1):207-214.

21. Bunn HF, Ransil BJ, Chao A. The interaction between erythrocyte organic phosphates, magnesium ion, and hemoglobin. J Biol Chem. 1971;246(17):5273-5279.

22. Garby L, Gerber G, De Verdier CH. Binding of 2,3-diphosphoglycerate and adenosine triphosphate to human haemoglobin A. Eur J Biochem. 1969;10(1):110-115.

23. Shahbazi P, Maleknia N. General Biochemistry for Students of Medical Sciences. Tehran, Iran: Tehran University Press; 2001;(2):194.

24. Buchachenko AL, Kouznetsov DA, Orlova MA, Markarian AA. Magnetic isotope effect of magnesium in phosphoglycerate kinase phosphorylation. Proc Natl Acad Sci U S A. 2005;102(31):10793-10796.

25. Schmeichel AM, Schmelzer JD, Low PA. Oxidative injury and apoptosis of dorsal root ganglion neurons in chronic experimental diabetic neuropathy. Diabetes. 2003;52(1):165-171

26. Russell JW, Golovoy D, Vincent AM, et al. High glucose-induced oxidative stress and mitochondrial dysfunction in neurons. FASEB J. 2002;16(13):1738-1748.

27. Wang IC, Tai LA, Lee DD, et al. C(60) and water-soluble fullerene derivatives as antioxidants against radical-initiated lipid peroxidation. J Med Chem. 1999;42(22):4614-4620.

28. Motohashi N, Takahashi A, Mifune M, Saito Y. Inhibitory effects of water-soluble cationic manganese porphyrins on peroxynitrite-induced SOS response in Salmonella typhimurium TA4107/pSK1002. Mutat Res. 2004;554(1-2):165-174.

29. Pessoto FS, Inada NM, Nepomuceno Mde F, et al. Biological effects of anionic meso-tetrakis (para-sulfonatophenyl) porphyrins modulated by the metal center. Studies in rat liver mitochondria. Chem Biol Interact. 2009;181(3):400-408.

30. Astaneie F, Afshari M, Mojtahedi A, et al. Total antioxidant capacity and levels of epidermal growth factor and nitric oxide in blood and saliva of insulin-dependent diabetic patients. Arch Med Res. 2005; 36(4):376-381.

31. Afshari M, Larijani B, Rezaie A, et al. Ineffectiveness of allopurinol in reduction of oxidative stress in diabetic patients; a randomized, double-blind placebo-controlled clinical trial. Biomed Pharmacother. 2004;58(10):546-550.

32. Markovic Z, Trajkovic V. Biomedical potential of the reactive oxygen species generation and quenching by fullerenes (C60). Biomaterials. 2008;29(26):3561-3573.

33. Lin CY, Tsai PS, Hung YC, Huang CJ. L-type calcium channels are involved in mediating the anti-inflammatory effects of magnesium sulphate. Br J Anaesth. 2010;104(1):44-51.

34. Pajoumand A, Shadnia S, Rezaie A, Abdi M, Abdollahi M. Benefits of magnesium sulfate in the management of acute human poisoning by organophosphorus insecticides. Hum Exp Toxicol. 2004;23(12): 565-569.

35. De Leeuw I, Engelen W, De Block C, Van Gaal L. Long term magnesium supplementation influences favourably the natural evolution of neuropathy in Mg-depleted type 1 diabetic patients (T1dm). Magnes Res. 2004;17(2):109-114.
International Journal of Nanomedicine

\section{Publish your work in this journal}

The International Journal of Nanomedicine is an international, peerreviewed journal focusing on the application of nanotechnology in diagnostics, therapeutics, and drug delivery systems throughou the biomedical field. This journal is indexed on PubMed Central, MedLine, CAS, SciSearch $®$, Current Contents ${ } /$ Clinical Medicine,

\section{Dovepress}

Journal Citation Reports/Science Edition, EMBase, Scopus and the Elsevier Bibliographic databases. The manuscript management system is completely online and includes a very quick and fair peer-review system, which is all easy to use. Visit http://www.dovepress.com/ testimonials.php to read real quotes from published authors. 